\title{
Defaults and Donation Decisions
}

\author{
Eric J. Johnson and Daniel G. Goldstein
}

\begin{abstract}
The well-documented shortage of donated organs suggests that greater effort should be made to increase the number of individuals who decide to become potential donors. We examine the role of one factor: the no-action default for agreement. We first argue that such decisions are constructed in response to the question, and therefore influenced by the form of the question. We then describe research that shows that presumed consent increases agreement to be a donor, and compare countries with opt-in (explicit consent) and opt-out (presumed consent) defaults. Our analysis shows that opt-in countries have much higher rates of apparent agreement with donation, and a statistically significant higher rate of donations, even with appropriate statistical controls. We close by discussing the costs and benefits associated with both defaults as well as mandated choice.
\end{abstract}

Keywords: Organ donation, Decision, Defaults, Policy.

(Transplantation 2004;78: 1713-1716)

$\mathrm{T}^{\mathrm{h}}$ he shortage of cadaveric organ donations is well known and has been documented extensively. Because demand has so clearly outstripped supply, there have been many suggestions of how to address the shortage, including calls for the establishment of a regulated market for the organs of the deceased $(1,2)$, suggestions for the payment of donors or donors' families $(3,4)$, and even suggestions that organs should become public property upon death (5). Calls for campaigns to change public attitudes (6) are widespread. Such proposals suggest that that people have a fixed attitude toward the costs and benefits of donation and require either financial incentives or a change in their attitudes. The implication in these cases is that people have made a decision about donation.

We would like to enrich this discussion by pointing out that the assumption that people have reached a decision not to donate may be mistaken. Instead of expressing well-articulated preferences, we will review evidence that the preference to become a donor is not well formed, suggesting the possibility that donation decisions are often constructed in response to the question. As a result, the form of the donation question influences its answers.

The implication of this constructive preference approach is important. It suggests that the problem of donor procurement is not one of changing people's choices through education or incentives. Instead, it suggests that the way in which a request to become a donor is framed will influence the outcome. In particular, the choice of default option may have significant effects on donation rates. Because the framing of organ donation questions is likely to require less investment than incentives, such as payment to donor's families or a market-based solution, it may be an attractive way of increasing social welfare.

The accompanying article by Mendelhoff et al. (7) assesses the quality-adjusted life years provided by the procurement of another donor, and suggests that the current cost of

\footnotetext{
This work was supported by grant SES 0352062 from the National Science Foundation to E.J. Johnson.

Center for the Decision Sciences, Columbia University Graduate School of Business, New York, NY.

Address for correspondence: Eric J. Johnson, Ph.D., Columbia Business School, Columbia University, 3022 Broadway, New York, NY 10027. E-mail: ejj3@columbia.edu.

Copyright (C) 2004 by Lippincott Williams \& Wilkins

ISSN 0041-1337/04/7812-1713
}

DOI: 10.1097/01.TP.0000149788.10382.B2 procuring an additional donor is markedly below its benefits. This suggests that there may be significant gains in social welfare to increasing spending for the procurement of organ donors. However, we suggest that increases in donation rate could be achieved, quite cost-effectively, through a change in the way the question is asked.

In the remainder of this article, we first provide an overview of constructive preferences in general and the specific role of default options. We then report on our experimental research examining the role of defaults in the decision to become a donor, and finally suggest how one might think about the costs and benefits of defaults.

\section{Defaults and Preference Construction}

Recent research in psychology depicts preferences as constructed, that is, not yet articulated in the minds of those who have not been asked $(8-11)$. Many demonstrations show that respondents' preferences, even for substantively important decisions, are influenced by factors which should not affect the choice. One of the now classic demonstrations (12) presented patients, graduate students, and physicians with the choice between two treatments-surgery or radiotherapy-for treatment of lung cancer. Half of each group saw the outcomes described as mortality rates, the other half saw survival rates. Although of course the descriptions portrayed the same outcomes, all three groups were affected by the different descriptions or frames. The mortality data resulted in an increase in choice for surgery, while the survival data resulted increased choices for radiation. We will return to this example below.

One factor that is particularly relevant to donor decisions is the choice of a default option. The impact of defaults have been shown by several inadvertent "natural experiments" in which governments, companies, and public agencies randomly assign people to one program and then give the chance to choose among a set of alternative ones-examples include assignment to health care plans (13), and the adoption of privacy policies $(14,15)$. These experiments show that random assignment to a default has a substantial role in determining what is chosen. In most cases, the majority of people choose the default option to which they were assigned. Two examples make the point in areas, such as organ donation, where the stakes are high. 
The first example involves automobile insurance. Both New Jersey and Pennsylvania attempted to deal with increased auto insurance costs, caused in part by fraud, by giving buyers of auto insurance a choice between a more expensive "full tort" plan and a less expensive "limited tort" plan. The full tort plan provided the right to sue for pain and suffering. The limited tort plan covered the medical costs of the insured, but removed the right to sue for difficult-to-prove "pain and suffering" claims. The idea behind the policy was that "honest" drivers would have more incentive to choose the limited tort plan both because it was cheaper and because they were less likely to use the pain and suffering option. Less honest (and therefore more expensive to cover) drivers, among others, would tend to choose the full tort plan, constructing what economists call a separating equilibrium: these drivers' choices of the more expensive policy would increase its cost further (reflecting their fraudulent claims), while not affecting the limited tort drivers. However, reality and economic theory did not match. This was confirmed by a natural experiment where New Jersey and Pennsylvania adopted different no-action defaults. New Jersey drivers were given the limited right to sue by default, while Pennsylvania drivers had the opposite default, the full right to sue. Interestingly, 79\% of New Jersey drivers "preferred" the limited right to sue, while in Pennsylvania, 70\% "preferred" the opposite plan. A psychological study in which people were assigned one of the two tort plans by default confirmed this: the full right to sue was chosen $53 \%$ of the time when it was the default, but only $23 \%$ of the time when it was not (16).

The second example involves retirement savings plans, the most important financial decision facing most Americans. In the United States, many workers are covered by a defined contribution plan, a 401(k) plan for example, in which people elect to save between $0 \%$ and $12 \%$ of their income for retirement. The plans are attractive: the contributions are in pretax dollars, the money compounds tax-free, and the first $6 \%$ is often matched by an employer. Consistent with observations that Americans are not saving sufficiently toward retirement, many initially contribute the default, that is, nothing. However, one recent study (17) changed the default, and found a marked increase in savings. One firm raised the default contribution from $0 \%$ to $3 \%$ and saw the percentage of new employees saving anything towards retirement rise from $31 \%$ to $86 \%$. However, the effect was almost too powerful-the $3 \%$ default surprisingly decreased the number of people electing to save more than $3 \%$. This result has been replicated in several firms (18), raising questions about what default is optimal. Could this be rational inaction? This seems unlikely because the economic stakes are simply too large (13). Why, then, is there a difference?

If preferences are constructed, defaults can influence choices in three ways. First, decision makers might believe that defaults are suggestions by the policy maker, implying a recommended action. Second, making a decision often involves effort while accepting the default is effortless. Many people would rather avoid making an active decision about donation, since it can be unpleasant and stressful (19). Physical effort such as filling out a form and tracking down a postage stamp may also increase acceptance of the default (13). Finally, defaults often represent the existing state or status quo, and change usually involves a trade-off, giving up one thing for another. For example, respondents to our research often suggest that becoming a donor yields satisfaction, which they think of as a gain, and contemplate how their gift might benefit others. However, they also often mention a loss, contemplating a body no longer intact. Because psychologists have shown that losses loom larger than the equivalent gains, a phenomenon known as loss aversion (20), changes in the default may result in a change of choice. For current nondonors, changing status (becoming a donor) involves the tradeoff between a gain (satisfaction) and a loss (the possible the negative imagery). For donors, changing status alters the tradeoff-losing the satisfaction, while gaining freedom from negative imagery. In each case, loss aversion suggests an increased weighting of what is foregone, making the default seem more attractive. The same logic explains why describing treatments using survival rates or mortality rates results in different choices among therapies. Mortality rates emphasize the probability of dying, obviously a loss, while survival rates emphasize the probability of living.

\section{Defaults and Organ Donations}

Over the course of the last two decades, a number of European countries have been running similar natural experiments with organ donation. Different countries have chosen different default options for the decision to become organ donors. Some countries require explicit consent and opting-in to become a donor, while others presume consent and require opting-out for those who do not want to be donors (21).

We first examined the role of defaults using an online experiment. We asked 161 respondents whether they would be donors using one of three questions with varying defaults. In the opt-in condition, participants were told to assume that they had just moved to a new state where the default was to not be an organ donor and they were given a choice to confirm or change that status. The opt-out condition was identical, except the default was to be a donor. The third, neutral condition simply required them to choose with no prior default. In all conditions, respondents could at a mouse click change their choice, largely eliminating effort explanations.

The default had a dramatic impact, with revealed donation rates being about twice as high when opting-out as when opting-in. As can be seen in Figure 1, the opt-out condition did not differ significantly from the neutral condition, which required a choice without a default option. Only the opt-in condition, the current practice in the United States, was significantly lower.

Because there are many factors that might produce different effects in the real world, we examined the rate of agreement to become a donor across European countries with explicit and presumed consent laws. With data reported in Gäbel (22), which we supplemented by contacting central registries for several countries, we estimated the effective consent rate, that is the number of people who had opted in (in explicit consent countries) or the number who had not opted out (in presumed consent countries). If preferences concerning organ donation are strong, defaults should have little or no effect. However, as can be seen in Figure 2, defaults make a large difference, with the four opt-in countries on the left having lower rates than the six opt-out countries on the right. The result is surprisingly strong: the two distributions have 


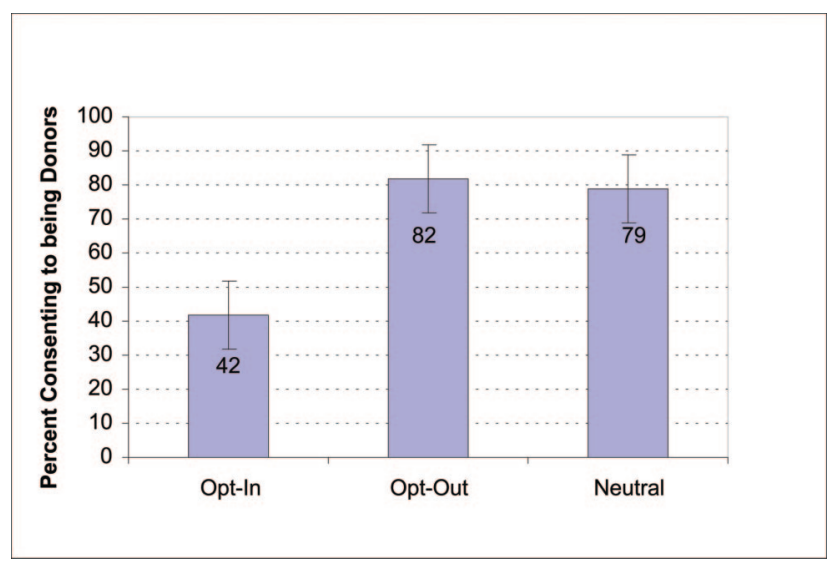

FIGURE 1. Effective consent rates, online experiment, by default.

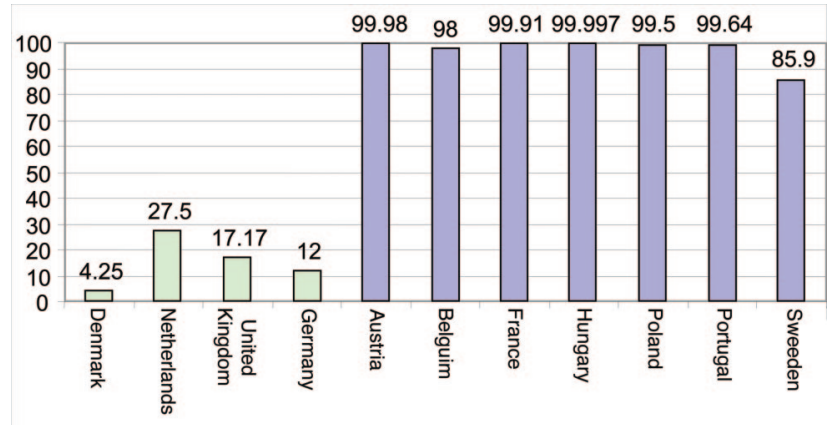

FIGURE 2. Effect consent rates by country. The four leftmost bars are explicit consent (opt-in). The seven rightmost bars are presumed consent (opt-out).

no overlap and nearly 60 percentage points separate the two groups. We think these effects are larger than those in our questionnaire because the cost of changing from the default is higher, involving filling out forms, making phone calls, or sending mail.

Some of the opt-in countries have tried hard to increase donations. The Netherlands, for example, accompanied the creation of their national registry with an extensive educational campaign and a mass mailing (of more than 12 million letters in a country of 15.8 million) asking citizens to register, but this failed to change the effective consent rate (23).

Could changes in default have an effect on the actual number of donations in a country? We examined the actual number of cadaveric donations made per million on a slightly larger list of countries, here using a time series of data from 1991-2001. We used a regression analysis that controlled for other differences in countries' propensity toward donation, transplant infrastructure, educational level, and religion-all variables known to affect donation rates, see Gimble et al. (24). While there are no differences across years, there is a strong effect of the default. Figure 3 shows that when donation is the default, there is a significant $(P<0.02)$ increase in donation, increasing from 14.1 to 16.4 , a $16.3 \%$ increase. Using similar techniques, but looking only at 1999 for a broader set of countries, including many more from Eastern Europe,

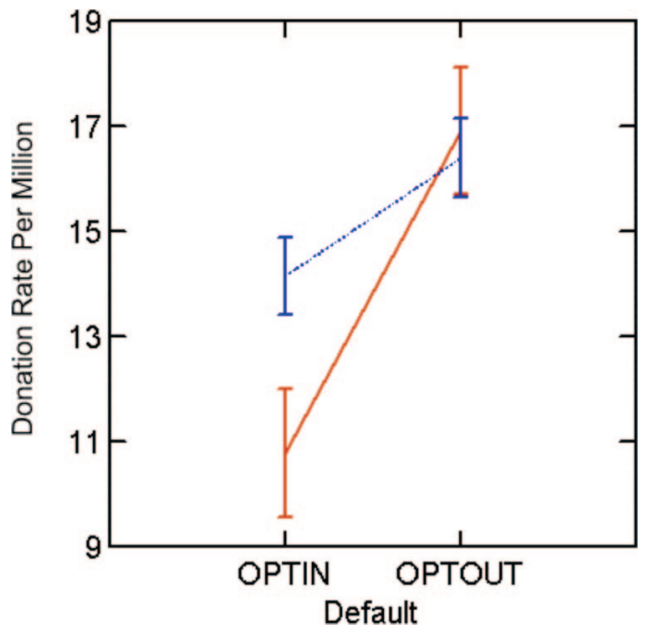

FIGURE 3. Estimated mean donation rate, 1991-2001, in donors per million as a function of default (opt-in vs. optout) for a time series analysis (blue line, data from this paper) and a cross-sectional analysis (red line, data from Gimbel et al.).

Gimbel et al. (24) report an increase from 10.8 to 16.9 , a $56.5 \%$ increase also plotted in Figure 3.

Of course any choice of default has its costs and benefits. To help illustrate that, we characterize those costs in Table 1 .

\section{CONCLUSION}

We close with three observations. First, almost every public policy has a no-action default, and the wise selection of defaults entails a balance between these costs. Using Table 1, it would seem that the possible misclassification of nondonors as donors must be balanced by the forgone lives saved. One consideration in making this choice would be the number of people who, when forced to chose, decide to become donors. In Table 1, we use the results of our web survey neutral condition to describe the stated preference (79\% for donation). It is difficult to estimate the realized categories, since the procedures used to obtain agreement are often complex and depend upon the agreement of family members.

Second, the idea that preferences are constructed provides an important alternative to views that incentives are required to increase the rate of donation. The available data suggest that most Americans approve of organ donation in

TABLE 1. Relationship between Defaults, Categorization, and Types of Errors

Realized Intended Categorization

\begin{tabular}{lcc}
\cline { 2 - 3 } Categorization & Donor (79\%) & Not Donor (21\%) \\
\hline Donor & $\begin{array}{c}\text { Correct classification; } \\
\text { additional lives saved }\end{array}$ & $\begin{array}{c}\text { Incorrect classification, } \\
\text { potential for } \\
\text { indignation, negative } \\
\text { publicity }\end{array}$ \\
Not Donor & $\begin{array}{c}\text { Incorrect classification; } \\
\text { potential lives saved } \\
\text { forgone. }\end{array}$ & Correct classification \\
\hline
\end{tabular}


the abstract but that far fewer have decided to become donors. Our diagnosis is that they have not made a decision, and the resulting prescription suggests that defaults will have a significant role in determining their status.

Finally, there is another cost, not considered in Table 1, and that is the cost of making a decision. Since people consider this question aversive, there is some utility to defaults, which allow people not to make choices, as opposed to mandated choice paradigms. In fact, the current experience in mandated choice is instructive. When the state of Virginia adopted a policy of forcing people to make a choice, over $24 \%$ refused to report a preference (25), consistent with the idea that forming a preference is cognitively costly. Defaults not only make a difference in what is chosen, they can also make decisions easier.

\section{REFERENCES}

1. Clay M, Block W. A free market for human organs. J Soc Pol Econ Stud 2002; 27: 227.

2. Editorial: An ethically defensible market in organs. Brit Med J 2002; 325:114.

3. Harris C, E., Alcorn SP. To solve a deadly shortage: economic incentives for human organ donation. Issues Law Med 2001; 3: 213.

4. Josefson D. AMA considers whether to pay for donation of organs. Brit Med J 2002; 324: 1541.

5. Harris J. Organ procurement-dead interests, living needs. J Med Ethics 2003;29:196.

6. Wolf JS, Servino EM, Nathan HN. National strategy to develop public acceptance of organ and tissue donation. Transplant Proc 1997; 29: 1477.

7. Mendeloff J, Ko K, Roberts MS, et al. Procuring organ donors as a health investment: how much should we be willing to spend? Transplantation 2004; 78: 1704.

8. Fischhoff B. Value elicitation: is there anything in there? Am Psychol 1991; 46: 835 .
9. Payne JW, Bettman JR, Johnson EJ. Behavioral decision research: A constructive processing perspective. Ann Rev Psychol 1992; 43: 87.

10. Slovic P. The construction of preference. Am Psychol 1995; 50: 364.

11. Kahneman D, Tversky A. Choices, Values, and Frames: Cambridge University Press, 2000.

12. McNeil BJ, Pauker SG, Sox HC, Tversky A. On the elicitation of preferences for alternative therapies. New Engl J Med 1982; 306: 1259

13. Samuelson W, Zeckhauser R. Status Quo Bias in Decision-Making. J Risk Uncertainty 1988; $1: 7$.

14. Bellman S, Johnson EJ, Lohse GL. To opt-in or opt-out? It depends on the question. Comm Acm 2001; 44: 25.

15. Johnson EJ, Bellman S, Lohse GL. Defaults, framing and privacy: Way opting in-opting out. Marketing Lett 2002; 13: 5.

16. Johnson EJ, Hershey J, Meszaros J, Kunreuther H. Framing, probability distortions, and insurance decisions. J Risk Uncertainty 1993; 7: 35.

17. Madrian BC, Shea D. The power of suggestion: An analysis of $401(\mathrm{k})$ participation and saving behavior. Quart J Econ 2001;116:1149.

18. Choi J, Laibson D, Madrian B, Metric A. For better or for worse: default effects and $401(\mathrm{k})$ savings behavior. In: Wise D, ed. Perspectives in the Economics of Aging. Chicago, University of Chicago Press 2001, pp. $81-121$

19. Baron J, Ritov I. Reference points and omission bias. Org Behav Human Decision Proc 1994; 59: 475.

20. Tversky A, Kahneman D. Loss Aversion in Riskless Choice - a reference-dependent model. Quart J Econ 1991; 106: 1039.

21. Johnson EJ, Goldstein D. Medicine - Do defaults save lives? Science 2003; 302: 1338 .

22. Gäbel H. Donor and Non-Donor Registries in Europe. Stockholm, Sweden: on behalf of the committee of experts on the Organizational Aspects of Co-operation in Organ Transplantation of the Council of Europe. 2002.

23. Oz MC, Kherani AR, Rowe A, et al. How to improve organ donation: Results of the ISHLT/FACT poll. J Heart Lung Transplant 2003; 22: 389.

24. Gimbel RW, Strosberg MA, Lehrman SE, et al. Presumed Consent and Other Predictors of Cadaveric Organ Donation in Europe. Prog Transplant 2003; 13: 17.

25. Klassen AC, Klassen DK. Who Are the Donors in Organ Donation? The Family's Perspective in Mandated Choice. Ann Int Med 1996; 125:70. 